\title{
Modelo numérico do transporte de nitrogênio no solo. Parte II: Reações biológicas durante a lixiviação
}

\author{
Felizardo A. Rocha ${ }^{1}$, Mauro A. Martinez ${ }^{2}$, Antônio T. Matos ${ }^{2}$, Reinaldo B. Cantarutti ${ }^{3}$ \& Joseane O. da Silva ${ }^{4}$
}

\begin{abstract}
RESUMO
Analisar o efeito da temperatura e umidade do solo nos processos de mineralização e nitrificação do nitrogênio e comparar as concentrações de nitrato e amônio, simuladas pelo modelo SIMASS-C, com aquelas obtidas experimentalmente, foi o objetivo que norteou o presente trabalho, razão por que se conduziram dois experimentos, o primeiro em câmeras de incubação, variando temperatura e teor de água do solo, e um segundo, em colunas de lixiviação montadas em laboratório. A temperatura e a umidade afetaram as transformações de nitrogênio, cujos efeitos foram mais pronunciados a partir de 15 dias de incubação, sobretudo nas temperaturas acima de $25{ }^{\circ} \mathrm{C}$ e umidades superiores à capacidade de campo. Ao se estimular as reações biológicas sofridas pelo nitrogênio, altos teores de água no solo causaram maiores erros entre as concentrações de nitrato e amônio simuladas e observadas.
\end{abstract}

Palavras-chave: transporte de água e solutos, simulação, nitrato, amônio

\section{Numerical model of nitrogen transport in the soil. Part II: Biological reaction during leaching}

\begin{abstract}
This work aimed at analyzing the effect of temperature and humidity of the soil on mineralization and nitrification processes of the nitrogen, as well as to compare nitrate and ammonium concentrations, simulated by the model SIMASS-C, with those observed. Two experiments were performed: the first in biological incubation camara, varying temperature and water content of the soil and the second, in columns in laboratory. The temperature and water content affected the transformations of nitrogen, and the effects were more pronounced after 15 days of incubation, mainly at temperatures above $25{ }^{\circ} \mathrm{C}$ and for water content higher than field capacity. By estimates of the biological reactions of nitrogen, higher levels of soil water caused larger errors between observed and simulated nitrate and ammonium concentrations.
\end{abstract}

Key words: water and solute transport, simulation, nitrate, ammonium

1 DEBI/UESB, CEP 45700-000, Itapetinga, BA. Fone: (77) 3261-8609. E-mail: felizardo@uesb.br

${ }^{2}$ DEA/UFV, CEP 36570-000, Viçosa, MG. Fone: (31) 3899-1910. E-mail: mmauro@ufv.br

3 DPS/UFV, Fone: (31) 3899-1860. E-mail: cantarutti@ufv.br

${ }^{4}$ CCTA/UENF, CEP 28013-600, Campos dos Goytacazes, RJ. Fone: (22) 2734-4823. E-mail: joseane@uenf.br 


\section{INTRODUÇÃO}

O estudo do movimento dos nutrientes no solo constitui tema importante na proposição de um manejo adequado da fertirrigação, com o objetivo de disponibilizar os nutrientes na profundidade de máxima densidade do sistema radicular; desta forma, além de otimizar a fertirrigação serão evitadas perdas de nutrientes para o lençol freático e, por conseguinte, para mananciais e rios (Bernando, 1994).

Em adubações nitrogenadas, essenciais às plantas e normalmente aplicadas em altas concentrações, ocorre a transformação de formas de nitrogênio não absorvíveis pelas plantas em formas absorvíveis e vice-versa, dificultando o entendimento de seu comportamento no solo com o propósito de estimar a sua disponibilidade; trata-se, portanto, de um elemento bastante dinâmico no solo.

O processo de mineralização do nitrogênio (N) é influenciado, dentre outros fatores, pela temperatura e teor de água do solo. De modo geral, o aumento da temperatura acelera as reações químicas e o metabolismo dos microrganismos (Serrano, 1997). A taxa de mineralização é alta quando a temperatura está na faixa de 30 a $35^{\circ} \mathrm{C}$ e menor para temperaturas acima ou abaixo desses valores (Reis \& Rondella, 2002).

Stanford \& Epstein (1974) mostraram que a mineralização do nitrogênio diminui com a redução do teor de água no solo, considerando teores de água no solo inferiores à capacidade de campo. Em teores de água acima da capacidade de campo, também proporciona diminuição na taxa de mineralização do nitrogênio devido à redução na concentração de oxigênio necessário às reações de mineralização pois, conforme Strong \& Fillery (2002) a taxa de decomposição por bactérias aeróbias é muito maior do que a de bactérias anaeróbias, uma vez que aquelas são mais eficientes energeticamente. Nesta situação, ocorrem também microssítios anaeróbios e, conseqüentemente, desnitrificação.

Não é somente o teor de água no solo que é importante mas, também, a sua variação temporária, isto é, os ciclos de secagem e umedecimento do solo têm profundo efeito na taxa de mineralização. Há evidências de que o reumedecimento do solo aumenta a atividade microbiológica no solo (Campbell \& Biederbeck, 1982).

Estudando a mineralização em vários solos da Argentina, variando temperatura e umidade em câmaras de incubação, Sierra (1997) observou que a condição ótima para a mineralização ocorreu a umidade equivalente à tensão de $30 \mathrm{kPa}$. O autor constatou que a temperatura influenciou mais a mineralização que a umidade do solo.

Black \& Waring (1976a) verificaram intensa mobilidade de $\mathrm{N}_{-} \mathrm{NO}_{3}{ }^{-}$através de uma camada de solo de 0 a $15 \mathrm{~cm}$, confirmando a hipótese de haver baixa adsorção de $\mathrm{N}_{-} \mathrm{NO}_{3}{ }^{-}$ nesta zona, devido à maior densidade de cargas negativas decorrentes da presença de matéria orgânica; constataram que a mobilidade se tornava maior quanto maior fosse a concentração de $\mathrm{N}$ aplicada.

A lixiviação de nitratos no solo pode alcançar grande magnitude se este ânion estiver presente no solo em quantidades acima da capacidade de absorção pela cultura e quando a irrigação ou chuva exceder a capacidade de armazenagem de água do solo; neste caso, e em razão de sua alta solubilidade em água, o nitrato pode ser lixiviado por fluxo de massa vindo a acompanhar a água de recarga dos aqüíferos subterrâneos (Muchovej \& Rechcigl, 1994; Owens, 1994).

Várias pesquisas têm sido feitas no sentido de elucidar os processos de perda de amônio e nitrato, tanto em relação ao escape da exploração radicular quanto em relação à contaminação de mananciais de água; há contudo, necessidade de se aprofundar o conhecimento sobre a mobilidade destes íons em solos tropicais, tendo em vista a possibilidade de ocorrência de uma densidade maior de cargas positivas em subsuperfície (Black \& Waring, 1976b).

Como as transformações a que o $\mathrm{N}$ está sujeito e suas interações no solo podem ocorrer simultaneamente ao movimento de água, como acontece freqüentemente em áreas fertirrigadas, fica evidente a importância da compreensão dos processos de mineralização e nitrificação do nitrogênio, de forma conjunta, para o entendimento da dinâmica do nitrogênio no solo, não só do ponto de vista da fisiologia da planta e da fertilidade do solo mas, também, do ponto de vista ambiental.

Dessa forma, os modelos físico-matemáticos constituem valiosa ferramenta no estudo do transporte de nutrientes no solo. Nesses modelos, procura-se descrever o estado atual e prever o comportamento futuro do movimento dos elementos no perfil do solo, contribuindo para o uso adequado da fertirrigação na agricultura, como é o caso do SIMASS-C, desenvolvido por Corrêa (2001).

Os principais objetivos com este trabalho, foram: a) verificar a influência da temperatura e umidade do solo nas reações biológicas, envolvendo o nitrogênio; e b) e seus efeitos no transporte de nitrato e amônio, simulados pelo modelo SIMASS-C modificado.

\section{MATERIAL E MÉTODOS}

Realizaram-se dois experimentos, o primeiro em câmara de incubação, variando temperatura e umidade, ao longo de seis épocas de incubação, e um segundo, em colunas de lixiviação, preenchidas com amostras de dois tipos de solo visando analisar a concentração de nitrato e amônio no perfil. As características do solo são descritas na Tabela 1. As amostras de solo foram secadas ao ar, passadas em peneiras com malha de $2 \mathrm{~mm}$ e homogeneizadas, antes do preenchimento e montagem das colunas.

\section{Experimento em câmaras de incubação}

Os tratamentos consistiram de três temperaturas (15, 25 e $35^{\circ} \mathrm{C}$ ) três teores de água no solo 20 , 30 e $42 \%$, no de textura muito argilosa e 10, 22 e $35 \%$, no de textura francoargilo-arenosa, ambos em base peso. Os valores extremos de umidade citados equivalem, aproximadamente, às tensões de $1500 \mathrm{kPa}$ (ponto de murcha) e $33 \mathrm{kPa}$ (capacidade de campo), tanto para o solo argiloso quanto para o franco-argiloarenoso; em seguida, amostras de solo úmido equivalentes a 
Tabela 1. Características físicas e químicas das amostras dos solos usados no experimento

\begin{tabular}{|c|c|c|c|}
\hline Características(1) & $\begin{array}{l}\text { Solo LE } \\
(0-40 \mathrm{~cm})\end{array}$ & $\begin{array}{l}\text { Solo LA } \\
(0-40 \mathrm{~cm})\end{array}$ & $\begin{array}{c}\text { Solo LA } \\
(40-60 \mathrm{~cm})^{(2)}\end{array}$ \\
\hline Classe textural & $M A^{(3)}$ & $\mathrm{FAA}^{(4)}$ & FAA \\
\hline Areia grossa (dag kg-1) & 20 & 48 & 51 \\
\hline Areia fina (dag kg-1) & 9 & 15 & 13 \\
\hline Silte $\left(\right.$ dag $\left.\mathrm{kg}^{-1}\right)$ & 8 & 6 & 6 \\
\hline Argila $\left(\right.$ dag $\left.\mathrm{kg}^{-1}\right)$ & 63 & 31 & 30 \\
\hline Massa específica $\left(\mathrm{g} \mathrm{cm}^{-3}\right)$ & 1,16 & 1,30 & 1,28 \\
\hline Porosidade (\%) & 51,50 & 48,61 & 47,80 \\
\hline pH em KCl $(1: 2,5)$ & 4,61 & 4,31 & - \\
\hline$P\left(\mathrm{mg} \mathrm{dm}^{-3}\right)$ & 2,1 & 4,2 & - \\
\hline $\mathrm{K}\left(\mathrm{mg} \mathrm{dm}{ }^{-3}\right)$ & 845 & 69 & - \\
\hline $\mathrm{Na}\left(\mathrm{mg} \mathrm{dm}^{-3}\right)$ & 4,0 & 9,0 & - \\
\hline $\mathrm{Ca}^{2+}\left(\mathrm{cmol}_{\mathrm{c}} \mathrm{dm}^{-3}\right)$ & 0,87 & 0,64 & - \\
\hline $\mathrm{Mg}^{2+}\left(\mathrm{cmol}_{\mathrm{c}} \mathrm{dm}^{-3}\right)$ & 0,25 & 0,14 & - \\
\hline $\mathrm{Al}^{3+}\left(\mathrm{cmol}_{\mathrm{c}} \mathrm{dm}^{-3}\right)$ & 0,00 & 0,80 & - \\
\hline $\mathrm{H}+\mathrm{Al}\left(\mathrm{cmol}_{\mathrm{c}} \mathrm{dm}^{-3}\right)$ & 5,6 & 6,3 & - \\
\hline MO (dag kg-1) & 3,73 & 2,74 & - \\
\hline
\end{tabular}

(1) Utilizou-se a metodologia da EMBRAPA (1997); (2) não foram feitas análises químicas da camada de 40-60 cm; (3) FA - muito argilosa; (4) FAA - Franco-argilo-arenosa

$40 \mathrm{~g}$ de solo seco, foram colocadas em recipientes plásticos de $80 \mathrm{~mL}$ de capacidade, de forma a se obter a densidade do solo, conforme Tabela 1.

Posteriormente, realizou-se a realizada adubação nitrogenada dos solos com sulfato de amônio, $\left(\mathrm{NH}_{4}\right)_{2} \mathrm{SO}_{4}$, via solução, com uma concentração equivalente a $400 \mathrm{~kg} \mathrm{ha}^{-1}$ de $\mathrm{N}$, com auxílio de uma pipeta de $5 \mathrm{~m}$; logo após a adubação nitrogenada, os recipientes com solo foram colocados nas câmaras de incubação (BOD); em cada BOD foi fixada uma temperatura, segundo os tratamentos propostos. O teor de água no solo foi controlado mediante pesagem em balança de precisão com duas casas decimais, a cada $24 \mathrm{~h}$, repondose o volume de água evaporado, quando necessário.

Aos 3, 7, 15, 30, 45 e 60 dias de incubação, as amostras de solo contidas nos recipientes plásticos foram retiradas, homogeneizadas, acondicionadas em sacos plásticos e congeladas para posterior análise das concentrações de $\mathrm{N}_{-} \mathrm{NH}_{4}{ }^{+}$ e $\mathrm{N}_{-} \mathrm{NO}_{3}{ }^{-}$; esses valores foram usados para parametrizar equações exponenciais a fim de descrever a variação na concentração do nitrogênio, ao longo do tempo, para isto, foram incorporadas ao modelo SIMASS-C.

A determinação da concentração de $\mathrm{NH}_{4}{ }^{+}$se deu utilizando-se o método descrito por Kempers \& Zweers (1986), e de nitrato, conforme Yang et al. (1998).

\section{Experimento em colunas de lixiviação}

As unidades experimentais se compunham de colunas com solo e de tubo de PVC rígido, com diâmetro nominal de $75 \mathrm{~mm}$ e altura de $45 \mathrm{~cm}$ (solo muito argiloso) e $65 \mathrm{~cm}$ (solo franco-argilo-arenoso), com seccionamento de $10 \mathrm{em} 10 \mathrm{~cm}$, para facilitar a desmontagem e as coletas das amostras, em diferentes profundidades, enquanto as colunas foram dispostas no delineamento em blocos casualizados na bancada de ensaio, constante de duas épocas de coleta e três repetições por época, ou seja, a cada época eram desmontadas 3 colunas (para cada solo).
Imediatamente após a aplicação do fertilizante, semelhante ao experimento em B.O.D., três colunas de cada solo foram desmontadas e amostras de solo foram retiradas nas profundidades de $0,10,20,30$, e $40 \mathrm{~cm}$, para o solo muito argiloso, e nas de $0,10,15,20,30,40,50$ e $60 \mathrm{~cm}$, no francoargilo-arenoso, para obtenção das concentrações de $\mathrm{N}_{-} \mathrm{NH}_{4}{ }^{+}$ e $\mathrm{N}_{-} \mathrm{NO}_{3}{ }^{-}$e teor de água no solo, referentes às condições iniciais e contorno para simulação.

Realizou-se, durante o experimento, duas irrigações; a segunda, realizada 10 dias após a primeira, sendo as colunas relativas à primeira irrigação desmontadas imediatamente antes da segunda irrigação; na primeira irrigação se aplicou uma lâmina média de $51 \mathrm{~mm}$, no solo franco-argilo-arenoso, e de $32,1 \mathrm{~mm}$, no solo muito argiloso; na segunda irrigação, a lâmina média de $21 \mathrm{~mm}$ foi aplicada, no solo franco-argilo-arenoso, e de $22,3 \mathrm{~mm}$, no solo muito argiloso.

Durante a simulação várias condições de contorno foram usadas, à medida em que o cenário o exigia.

\section{RESULTADOS E DISCUSSÃO}

\section{Influência da temperatura e umidade na mineralização e nitrificação}

Os resultados do experimento de incubação obtidos ao final de seis períodos de incubação, para os dois solos analisados, estão apresentados nas Tabelas 2 e 3.

As maiores taxas de redução de amônio ao longo do tempo ocorreram quando o teor de água no solo foi equivalente à capacidade de campo (29\% no solo muito argiloso e $22 \%$ no solo franco-argilo-arenoso) ou superior (Tabelas 2 e 3), independentemente do solo e da temperatura. Gomes et al. (1998), observaram que, ao aplicar sulfato de amônio em condições aeróbias no solo, o amônio foi totalmente transformado para a forma nítrica após 20 a 30 dias da sua aplicação, diferente do observado neste experimento.

Nos tratamentos com temperatura de 25 ou de $35^{\circ} \mathrm{C}$ e o teor de água no solo na capacidade de campo, o $\mathrm{N}_{-} \mathrm{NH}_{4}^{+}$ praticamente desapareceu aos 60 dias de incubação (Tabelas 2 e 3); entretanto, na maior parte dos tratamentos havia amônio no solo aos 60 dias de experimento, sobretudo quando a temperatura ou a umidade foi baixa, mostrando que essas duas variáveis reduziram a taxa de nitrificação; nessas circunstâncias, a atividade dos microrganismos é reduzida, em virtude da falta de água aliada à baixa mobilidade dos mesmos, restringindo a dos microrganismos aos nutrientes necessários ao metabolismo.

Nos primeiros 30 dias de incubação a redução na concentração do $\mathrm{N}_{-} \mathrm{NH}_{4}{ }^{+}$variou de $19 \%$ (na menor temperatura e teor de água) a 93\% (na maior temperatura e teor de água), para o solo muito argiloso, enquanto no solo franco-argiloarenoso essas reduções foram de $28 \%$ (na menor temperatura e umidade) e $34 \%$ (na maior temperatura e teor de água), respectivamente; isto ocorreu porque o $\mathrm{N}^{-} \mathrm{NH}_{4}{ }^{+}$proveniente da matéria orgânica e da dissolução do sulfato de amônio no solo, foi convertido a nitrato.

Os tratamentos com maior teor de água no solo, para o solo arenoso e argiloso, apresentavam 93,6 e 94,6\% do espaço 
Tabela 2. Concentração de $\mathrm{N}-\mathrm{NH}_{4}{ }^{+}$e N-NO${ }_{3}^{-}$, do solo muito argiloso em seis períodos de incubação em função da temperatura e teor de água do solo

\begin{tabular}{|c|c|c|c|c|c|c|c|}
\hline \multicolumn{2}{|c|}{ Tratamentos } & \multicolumn{6}{|c|}{ Períodos de incubação (dias) } \\
\hline $\begin{array}{l}\text { Temperatura } \\
\left({ }^{\circ} \mathrm{C}\right)^{(1)}\end{array}$ & $\begin{array}{l}\text { Teor de água } \\
\left(\mathrm{kg} \mathrm{kg}^{-1}\right)^{(2)}\end{array}$ & 3 & 7 & 15 & 30 & 45 & 60 \\
\hline 15 & $\begin{array}{l}20 \\
29 \\
42\end{array}$ & $\begin{array}{l}215,4 \mathrm{aA} \\
205,1 \mathrm{aA} \\
175,3 \mathrm{aB}\end{array}$ & $\begin{array}{l}172,9 \mathrm{aA} \\
176,6 \mathrm{aA} \\
179,9 \mathrm{aA}\end{array}$ & $\begin{array}{c}\text { Concentração } \\
165,8 \mathrm{aA} \\
83,2 \mathrm{bB} \\
155,9 \mathrm{aA}\end{array}$ & $\begin{array}{r}\mathrm{l}^{+}(\mathrm{mg} \mathrm{kg} \\
173,5 \mathrm{aA} \\
47,6 \mathrm{aB} \\
155,8 \mathrm{aA}\end{array}$ & $\begin{array}{r}253,2 \mathrm{aA} \\
73,6 \mathrm{aC} \\
118,3 \mathrm{aB}\end{array}$ & $\begin{array}{r}227,3 \mathrm{aA} \\
110,3 \mathrm{aB} \\
3,6 \mathrm{aC}\end{array}$ \\
\hline 25 & $\begin{array}{l}20 \\
29 \\
42\end{array}$ & $\begin{array}{l}181,0 \text { bA } \\
211,0 \text { aA } \\
203,9 \text { aA }\end{array}$ & $\begin{array}{l}168,9 \mathrm{aA} \\
154,5 \mathrm{aA} \\
136,8 \mathrm{aB}\end{array}$ & $\begin{array}{r}176,5 \mathrm{aA} \\
154,7 \mathrm{aA} \\
90,2 \mathrm{bB}\end{array}$ & $\begin{array}{r}152,0 \mathrm{aA} \\
26,1 \mathrm{aB} \\
21,3 \mathrm{bB}\end{array}$ & $\begin{array}{r}240,6 \mathrm{aA} \\
1,9 \mathrm{bB} \\
5,9 \mathrm{bB}\end{array}$ & $\begin{array}{r}188,7 \mathrm{bA} \\
1,7 \mathrm{bB} \\
1,8 \mathrm{aB}\end{array}$ \\
\hline 35 & $\begin{array}{l}20 \\
29 \\
42\end{array}$ & $\begin{array}{l}168,1 \mathrm{bB} \\
201,5 \mathrm{aA} \\
169,7 \mathrm{cB}\end{array}$ & $\begin{array}{l}171,9 \mathrm{aA} \\
155,6 \mathrm{aA} \\
165,1 \mathrm{aA}\end{array}$ & $\begin{array}{r}149,0 \mathrm{aA} \\
85,93 \mathrm{bB} \\
75,83 \mathrm{bB}\end{array}$ & $\begin{array}{r}147,1 \mathrm{aA} \\
5,0 \mathrm{aB} \\
12,5 \mathrm{bB}\end{array}$ & $\begin{array}{r}152,8 \mathrm{bA} \\
1,5 \mathrm{bB} \\
1,9 \mathrm{bB}\end{array}$ & $\begin{array}{r}144,2 \mathrm{cA} \\
0,7 \mathrm{bB} \\
0,9 \mathrm{aB}\end{array}$ \\
\hline 15 & $\begin{array}{l}20 \\
29 \\
42\end{array}$ & $\begin{array}{l}31,2 \text { aA } \\
35,4 \text { aA } \\
32,6 \text { aA }\end{array}$ & $\begin{array}{l}32,0 \mathrm{aA} \\
31,2 \mathrm{aA} \\
30,5 \mathrm{aA}\end{array}$ & $\begin{array}{c}\text { Concentração } \\
29,1 \mathrm{aA} \\
29,8 \mathrm{cA} \\
32,3 \mathrm{bA}\end{array}$ & $\begin{array}{r}3_{3}^{-}\left(\mathrm{mg} \mathrm{kg}^{-1}\right. \\
43,3 \mathrm{bA} \\
46,8 \mathrm{cA} \\
43,6 \mathrm{cA}\end{array}$ & $\begin{array}{r}53,4 \mathrm{bC} \\
107,4 \mathrm{aB} \\
171,7 \mathrm{aA}\end{array}$ & $\begin{array}{r}58,3 \mathrm{cB} \\
191,7 \mathrm{aA} \\
42,7 \mathrm{aC}\end{array}$ \\
\hline 25 & $\begin{array}{l}20 \\
29 \\
42\end{array}$ & $\begin{array}{l}32,3 \text { aA } \\
34,6 \text { aA } \\
29,3 \text { aA }\end{array}$ & $\begin{array}{l}31,9 \text { aA } \\
36,1 \text { aA } \\
29,5 \text { aA }\end{array}$ & $\begin{array}{l}38,4 \mathrm{aB} \\
60,3 \mathrm{bA} \\
43,9 \mathrm{bB}\end{array}$ & $\begin{array}{r}59,3 \mathrm{bC} \\
346,5 \mathrm{bA} \\
260,5 \mathrm{bB}\end{array}$ & $\begin{array}{l}72,8 \mathrm{bA} \\
36,8 \mathrm{bB} \\
34,2 \mathrm{cB}\end{array}$ & $\begin{array}{l}90,3 \mathrm{bA} \\
45,0 \mathrm{bB} \\
42,7 \mathrm{aB}\end{array}$ \\
\hline 35 & $\begin{array}{l}20 \\
29 \\
42\end{array}$ & $\begin{array}{l}34,6 \mathrm{aA} \\
34,8 \mathrm{aB} \\
18,7 \mathrm{aC}\end{array}$ & $\begin{array}{l}33,6 \text { aA } \\
44,2 \text { aA } \\
31,9 \text { aA }\end{array}$ & $\begin{array}{r}84,3 \mathrm{aC} \\
209,8 \mathrm{aA} \\
188,7 \mathrm{aB}\end{array}$ & $\begin{array}{l}124,3 \mathrm{aC} \\
383,4 \mathrm{aA} \\
325,9 \mathrm{aB}\end{array}$ & $\begin{array}{r}122,7 \mathrm{aB} \\
41,9 \mathrm{bC} \\
165,4 \mathrm{bA}\end{array}$ & $\begin{array}{r}131,9 \mathrm{bA} \\
45,4 \mathrm{aB} \\
44,4 \mathrm{aB}\end{array}$ \\
\hline
\end{tabular}

(1) Médias seguidas da mesma letra minúscula, na coluna, não diferem entre si a $5 \%$ pelo teste de Tukey, variando temperatura e fixando umidade; (2) Médias seguidas da mesma letra maiúscula, na coluna, não diferem entre si a $5 \%$ pelo teste de Tukey, variando umidade e fixando temperatura

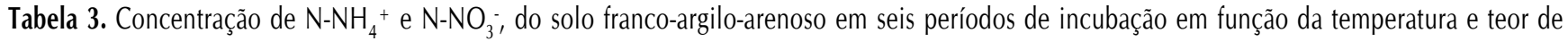
água do solo

\begin{tabular}{|c|c|c|c|c|c|c|c|}
\hline \multicolumn{2}{|c|}{ Tratamentos } & \multicolumn{6}{|c|}{ Períodos de incubação (dias) } \\
\hline $\begin{array}{l}\text { Temperatura } \\
\left({ }^{\circ} \mathrm{C}\right)^{(1)}\end{array}$ & $\begin{array}{l}\text { Teor de água } \\
\left(\mathrm{kg} \mathrm{kg}^{-1}\right)^{(2)}\end{array}$ & 3 & 7 & 15 & 30 & 45 & 60 \\
\hline 15 & $\begin{array}{l}10 \\
22 \\
35\end{array}$ & $\begin{array}{l}319,5 \mathrm{aA} \\
324,6 \mathrm{aA} \\
290,5 \mathrm{aB}\end{array}$ & $\begin{array}{l}288,6 \text { bA } \\
274,8 \text { aA } \\
286,9 \text { aA }\end{array}$ & $\begin{array}{c}\text { nncentração } \\
244,7 \text { aA } \\
243,6 \text { aA } \\
211,6 \text { aB }\end{array}$ & $\begin{array}{r}4^{+}\left(\mathrm{mg} \mathrm{kg}^{-}\right. \\
230,2 \mathrm{aA} \\
221,9 \mathrm{aA} \\
199,8 \mathrm{aB}\end{array}$ & $\begin{array}{l}263,5 \mathrm{aA} \\
245,8 \mathrm{aB} \\
207,4 \mathrm{aC}\end{array}$ & $\begin{array}{l}218,3 \mathrm{aA} \\
155,8 \mathrm{aB} \\
153,2 \mathrm{aB}\end{array}$ \\
\hline 25 & $\begin{array}{l}10 \\
22 \\
35\end{array}$ & $\begin{array}{l}326,8 \mathrm{aA} \\
257,1 \mathrm{bC} \\
278,1 \mathrm{aB}\end{array}$ & $\begin{array}{l}287,4 \text { bA } \\
286,6 \text { aA } \\
264,5 \text { aA }\end{array}$ & $\begin{array}{l}227,4 \mathrm{aA} \\
219,7 \mathrm{aA} \\
178,9 \mathrm{aB}\end{array}$ & $\begin{array}{r}249,7 \mathrm{aA} \\
93,5 \mathrm{bC} \\
134,1 \mathrm{bB}\end{array}$ & $\begin{array}{r}217,5 \mathrm{bA} \\
8,6 \mathrm{bC} \\
52,1 \mathrm{bB}\end{array}$ & $\begin{array}{r}183,5 \mathrm{bA} \\
3,3 \mathrm{bB} \\
0,1 \mathrm{bB}\end{array}$ \\
\hline 35 & $\begin{array}{l}10 \\
22 \\
35\end{array}$ & $\begin{array}{l}300,2 \text { aA } \\
278,1 \text { bA } \\
244.9 \text { bB }\end{array}$ & $\begin{array}{l}326,6 \mathrm{aA} \\
299,1 \mathrm{aB} \\
292,2 \mathrm{aB}\end{array}$ & $\begin{array}{l}222,2 \mathrm{aA} \\
217,4 \mathrm{aA} \\
187,8 \mathrm{aB}\end{array}$ & $\begin{array}{r}231,2 \mathrm{aA} \\
82,7 \mathrm{bC} \\
162,1 \mathrm{bB}\end{array}$ & $\begin{array}{r}113,5 \mathrm{cA} \\
2,2 \mathrm{bC} \\
67,6 \mathrm{bB}\end{array}$ & $\begin{array}{r}194,0 \mathrm{bA} \\
3,8 \mathrm{bC} \\
22,9 \mathrm{bB}\end{array}$ \\
\hline 15 & $\begin{array}{l}10 \\
22 \\
35\end{array}$ & $\begin{array}{l}19,1 \mathrm{aA} \\
20,8 \mathrm{aA} \\
11,5 \mathrm{aA}\end{array}$ & $\begin{array}{l}17,0 \mathrm{aA} \\
15,7 \mathrm{aA} \\
11,3 \mathrm{aA}\end{array}$ & $\begin{array}{c}\text { oncentraçã } \\
17,8 \mathrm{aA} \\
16,9 \mathrm{aA} \\
12,3 \mathrm{aA}\end{array}$ & $\begin{array}{r}3_{3}^{-}\left(\mathrm{mg} \mathrm{kg}^{-1}\right. \\
21,2 \mathrm{aA} \\
24,4 \mathrm{cA} \\
15,4 \mathrm{aA}\end{array}$ & $\begin{array}{l}36,1 \mathrm{bB} \\
65,7 \mathrm{aA} \\
30,1 \mathrm{bB}\end{array}$ & $\begin{array}{l}35,3 \mathrm{bB} \\
73,7 \mathrm{aA} \\
41,5 \mathrm{cB}\end{array}$ \\
\hline 25 & $\begin{array}{l}10 \\
22 \\
35\end{array}$ & $\begin{array}{r}24,5 \mathrm{aA} \\
22,1 \mathrm{aA} \\
5,5 \mathrm{aA}\end{array}$ & $\begin{array}{r}18,9 \mathrm{aA} \\
19,1 \mathrm{aA} \\
5,9 \mathrm{aA}\end{array}$ & $\begin{array}{r}22,2 \mathrm{aA} \\
34,0 \mathrm{aA} \\
7,1 \mathrm{aB}\end{array}$ & $\begin{array}{r}35,3 \mathrm{aB} \\
127,6 \mathrm{bA} \\
12,9 \mathrm{aC}\end{array}$ & $\begin{array}{r}76,9 \mathrm{bB} \\
37,3 \mathrm{aC} \\
133,9 \mathrm{bA}\end{array}$ & $\begin{array}{r}73,5 \mathrm{bB} \\
39,7 \mathrm{aC} \\
199,0 \mathrm{aA}\end{array}$ \\
\hline 35 & $\begin{array}{l}10 \\
22 \\
35\end{array}$ & $\begin{array}{l}18,0 \mathrm{aA} \\
20,5 \mathrm{aA} \\
10,1 \mathrm{aA}\end{array}$ & $\begin{array}{r}20,2 \mathrm{aA} \\
21,5 \mathrm{aA} \\
7,2 \mathrm{aB}\end{array}$ & $\begin{array}{r}27,7 \mathrm{aA} \\
32,0 \mathrm{aA} \\
7,3 \mathrm{aB}\end{array}$ & $\begin{array}{r}43,7 \mathrm{aB} \\
197,5 \mathrm{aA} \\
45,7 \mathrm{aB}\end{array}$ & $\begin{array}{r}131,2 \mathrm{aA} \\
37,3 \mathrm{aC} \\
90,7 \mathrm{aB}\end{array}$ & $\begin{array}{r}123,9 \mathrm{aB} \\
37,0 \mathrm{aC} \\
100,8 \mathrm{bA}\end{array}$ \\
\hline
\end{tabular}

(1) Médias seguidas da mesma letra minúscula, na coluna, não diferem entre si a $5 \%$ pelo teste de Tukey, variando temperatura e fixando umidade; (2) Médias seguidas da mesma letra maiúscula, na coluna, não diferem entre si a $5 \%$ pelo teste de Tukey, variando umidade e fixando temperatura

poroso preenchido com água, respectivamente; ou seja, havia baixa concentração de oxigênio nesses solos. Strong \& Fillery (2002), observaram que com $74 \%$ do espaço poroso do solo preenchido com água, a desnitrificação aumentou rapidamente.

Nos primeiros 30 dias de incubação foi alta a taxa de for- mação de nitrato, com aumento da concentração de 11,4\% (na menor temperatura e umidade) até 50,8\% (na maior temperatura e umidade), no solo franco-argilo-arenoso e de 38\% para 1644\%, no solo muito argiloso, respectivamente (Tabela 2 e 3).

Nas temperaturas de 25 e $35^{\circ} \mathrm{C}$ e com o solo na capacidade de campo ou superior, foi maior o acúmulo de $\mathrm{N}_{-} \mathrm{NO}_{3}{ }^{-}$, 
justificando as altas taxas de redução de amônio, em que o regime de umidade do solo intensificou a atividade dos microrganismos e, portanto, a nitrificação.

Apesar da alta taxa de aumento do $\mathrm{N}_{-} \mathrm{NO}_{3}{ }^{-}$ao longo do tempo em relação ao período inicial de incubação, o seu incremento não foi proporcional às reduções na concentração de $\mathrm{N}_{-} \mathrm{NH}_{4}{ }^{+}$, ficando evidente a possibilidade de imobilização e/ou desnitrificação, conforme constatado por autores como Gonçalves \& Carlyle (1994) mostrando a importância do teor de água durante o manejo da irrigação.

Strong \& Fillery (2002) constataram que mesmo em condições de não-saturação existem no solo microssítios em que não existe suprimento de $\mathrm{O}_{2}$ suficiente e o $\mathrm{NO}_{3}{ }^{-}$é usado como aceptor de elétrons.

Na temperatura de $15^{\circ} \mathrm{C}$ a atividade dos microrganismos autotróficos foi reduzida ocorrendo maior concentração de $\mathrm{N}-\mathrm{NH}_{4}{ }^{+}$no solo, independentemente do teor de água e solo (Tabelas 2 e 3). Comparando-se os dois solos na temperatura de $15^{\circ} \mathrm{C}$ e umidade no ponto de murcha, observou-se que, em média, concentrações de amônio maiores no solo franco-argilo-arenoso, devido à menor quantidade de água.

A baixos teores de água houve menor a formação de $\mathrm{N}-\mathrm{NO}_{3}{ }^{-}$, sendo esta inferior para o solo franco-argilo-arenoso, condições em que o baixo teor de água limitou a difusão e, conseqüentemente, o suprimento de substrato para os microrganismos. Os efeitos fisiológicos relativos a hidratação celular, podem explicar a redução da atividade dos microrganismos nitrificadores (Stark \& Firestone, 1995).

Nos tratamentos T25U22 (temperatura de $25{ }^{\circ} \mathrm{C}$ e teor de água no solo de 22\%), T35U22, para o solo franco-argiloarenoso e T25U42, T25U29 e T15U42, no solo muito argiloso, mostrados nas Tabelas 2 e 3, indicaram a ocorrência de decréscimo abrupto da concentração de $\mathrm{N}_{-} \mathrm{NO}_{3}{ }^{-}$após 30 dias de incubação, coincidindo com o período em que a concentração de $\mathrm{N}_{-} \mathrm{NH}_{4}{ }^{+}$estava baixa no solo; neste caso, acredita-se que a falta de substrato tenha causado redução da nitrificação.

As análises de variância (Tabelas 2 e 3), para os tratamentos umidade e temperatura, tiveram efeito na mineralização e nitrificação (5\% pelo teste F); em ambos os solos, somente a partir de 15 dias de incubação os efeitos de temperatura e umidade influenciaram, de forma mais evidente, as concentrações de amônio e nitrato. Não ficou evidente, porém, o efeito de um tratamento em relação ao outro, ou seja, temperatura em relação à umidade devido, provavelmente à grande instabilidade das formas de $\mathrm{N}$ no solo.

\section{Simulação da distribuição de nitrato e amônio no solo}

Na Tabela 4 estão apresentados os parâmetros de transporte utilizados como dado de entrada do modelo SIMASSC, simulação da dinâmica dos íons nitrato e amônio no solo.

A adsorção de íons é maior em solos com maiores coeficientes de partição $K_{d}$ e maior fator de retardamento R. Nos dois solos, os valores de $\mathrm{K}_{\mathrm{d}}$ e $\mathrm{R}$ para o íon amônio foram maiores em relação ao nitrato, em razão da existência de poros de maior diâmetro (macroporos) neste último, o que significa maior velocidade da água nos poros, fluxo de massa e menor interação com a matriz.
Tabela 4. Parâmetros de transporte do amônio e nitrato: coeficiente de partição $\left(K_{d}\right)$ e fator de retardamento $(R)$

\begin{tabular}{lccccc}
\hline \multirow{2}{*}{ Tipo de Solo } & \multicolumn{3}{c}{ Amônio } & & \multicolumn{3}{c}{ Nitrato } \\
\cline { 2 - 3 } \cline { 5 - 6 } Muito argiloso $^{(1)}$ & $\mathbf{K}_{\mathbf{d}}$ & $\mathbf{R}$ & & $\mathbf{K}_{\mathbf{d}}$ & $\mathbf{R}$ \\
Franco-argilo-renoso $^{(2)}$ & 1,021 & 3,299 & & 0,112 & 1,252 \\
Franco-argilo-renoso $^{(3)}$ & 0,734 & 2,964 & & 0,083 & 1,223 \\
\hline
\end{tabular}

(1) camada de $0-40 \mathrm{~cm}$; (2) camada de $0-40 \mathrm{~cm}$; (3) camada de $40-60 \mathrm{~cm}$ )

As simulações para estimativa da concentração do nitrato e amônio com o modelo SIMASS-C, consideraram o termo sem fonte de nitrogênio (SFN) e com fonte de nitrogênio (CFN), para o $\mathrm{NO}_{3}{ }^{-}$, e sem sumidouro nitrogênio (SSN) e com sumidouro de nitrogênio (CSN), para o $\mathrm{NH}_{4}{ }^{+}$, apenas para os primeiros $20 \mathrm{~cm}$ de profundidade.

Os perfis de concentração de nitrato e amônio observados e simulados após a primeira irrigação, para o solo arenoso, estão exibidos nas Figuras 1A e 1B.

Os perfis simulados e observados (Figura 1) mostram bom comportamento do modelo SIMASS-C modificado ao se estimar as concentrações de amônio e nitrato, mas, este último apresentou maiores erros entre os perfis, indicando uma forte influência que a componente convectiva tem sobre o movimento de $\mathrm{NO}_{3}{ }^{-}$no solo, uma vez que, logo após a aplicação de uma lâmina de irrigação, o teor de água no solo se eleva para próximo da saturação, deslocando $\mathrm{NO}_{3}{ }^{-}$por fluxo de fluxo de

A. Concentração de amônio (mg L $\left.{ }^{-1}\right)$

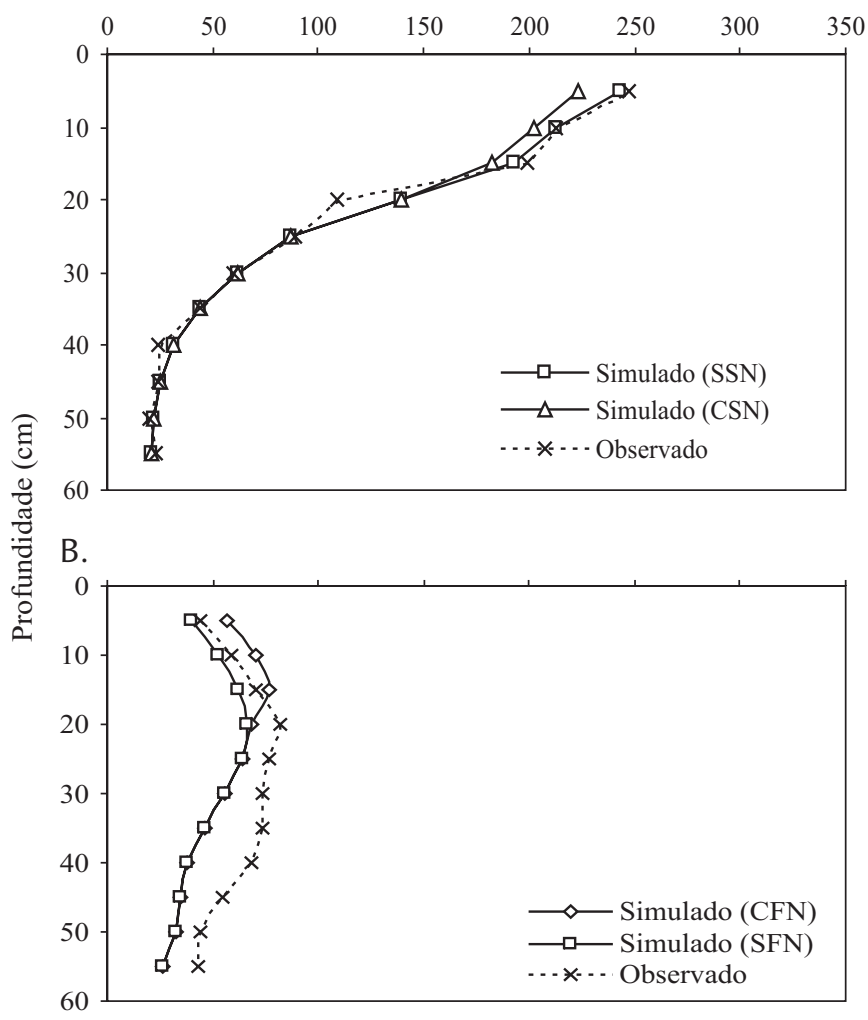

Figura 1. Perfis de concentração de $\mathrm{NH}_{+}{ }^{+}(\mathrm{A})$ e $\mathrm{NO}_{3}{ }^{-}$(B) em solo francoargilo-arenoso, observados experimentalmente e simulados pelo modelo SIMASS-C, sem fonte de $\mathrm{N}$ (SFN) e com fonte de $\mathrm{N}$ (CFN), para o $\mathrm{NO}_{3}^{-}$, e sem sumidouro $\mathrm{N}(\mathrm{SSN})$ e com sumidouro de $\mathrm{N}(\mathrm{CSN})$, para o $\mathrm{NH}_{4}{ }^{+}, 10$ dias após primeira irrigação 
massa; os valores de Kd e R reforçam esta hipótese; portanto, as características físico-hídricas do solo são fundamentais no estudo do movimento de íons no solo.

Ferreira et al. (1990), trabalharam com movimentação de $\mathrm{NO}_{3}{ }^{-}$em colunas de solo e observaram a ocorrência de fluxo de massa 4 h após a irrigação, em virtude da quase saturação do meio poroso e acentuada dispersão de $\mathrm{NO}_{3}{ }^{-}$, 48 h após a irrigação.

Quando se analisa a movimentação de nitrogênio, as reações biológicas também assumem importância significativa.

Os perfis considerando os termos CFN e CSN (Figuras 1A e 1B) subestimaram e superestimaram as concentrações de amônio e nitrato nos primeiros $20 \mathrm{~cm}$ de profundidade.

Os perfis representados pelas Figuras 2A e 2B, mostraram uma brusca redução na concentração de amônio entre a primeira e segunda irrigações, atingindo valores nulos abaixo de $30 \mathrm{~cm}$ de profundidade; contudo, esta redução no amônio não refletiu em um aumento proporcional de nitrato implicando de forma semelhante ao experimento de incubação, em perdas de nitrato por desnitrificação e/ou imobilização.

Visto que não houve lixiviação na base das colunas mas havia altos teores de água na base da coluna, próximos à saturação, conclui-se que a desnitrificação é a causa mais

A.
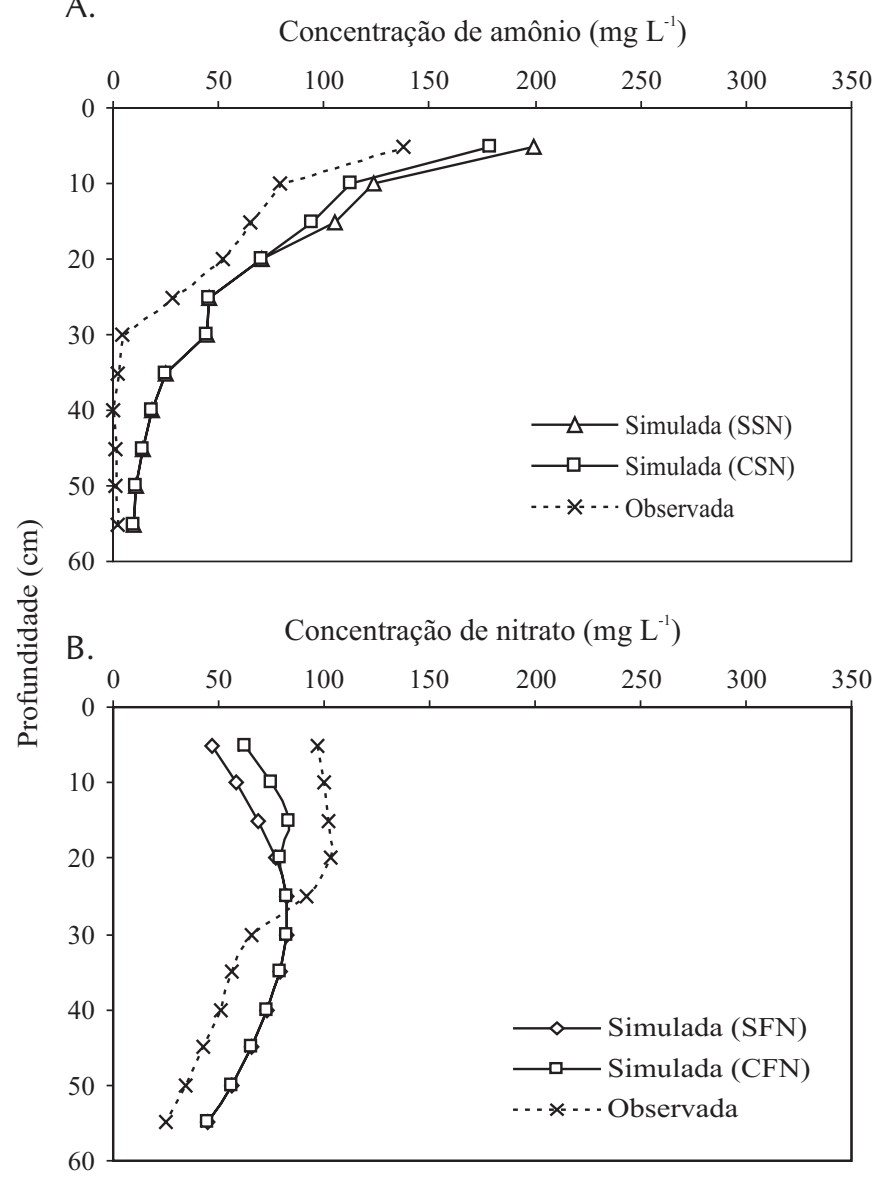

Figura 2. Perfis de concentração de $\mathrm{NH}_{4}{ }^{+}$(A) e $\mathrm{NO}_{3}$ - (B) em solo francoargilo-arenoso, observados e simulados pelo modelo SIMASS-C, sem fonte de $\mathrm{N}$ (SFN) e com fonte de $\mathrm{N}$ (CFN), para o $\mathrm{NO}_{3}^{-}$, e sem sumidouro $\mathrm{N}$ (SSN) e com sumidouro de $\mathrm{N}(\mathrm{CSN})$, para o $\mathrm{NH}_{4}{ }^{+}, 10$ dias após aplicação da segunda lâmina de irrigação provável das baixas concentrações de nitrato (Figuras 2A e 2B); portanto, é fundamental um manejo adequado da fertirrigação, mantendo a umidade dentro de faixas que evitem as perdas desnecessárias de $\mathrm{N}$ e, por conseguinte, redução nos custos de produção agrícola.

Apesar dos teores médios de água no solo utilizados como condições iniciais durante a simulação terem sido maiores para o solo muito argiloso em comparação com o franco-argilo-arenoso, ocorreu maior lixiviação de nitrato no solo franco-argilo-arenoso, comportamento que pode estar relacionado à menor capacidade de retenção de água e ao menor fator de retardamento do solo franco-argilo-arenoso.

Os perfis (Figuras 3A e 3B) mostraram que o modelo superestimou a concentração de amônio e nitrato, com maiores erros para este último. O método de determinação dos parâmetros de entrada Kd e $\mathrm{R}$ é uma das causas prováveis deste erro, haja vista que esses parâmetros foram determinados em condições de solo saturado, diferente das condições experimentais, exceto para os períodos imediatamente após eventos de irrigação.

Nos perfis das Figuras 3A e 3B, foi pequena a melhoria na estimativa das formas de $\mathrm{N}$ com a inclusão dos modelos que descrevem as reações biológicas do $\mathrm{N}$, justificando o estudo de outros modelos.

A.
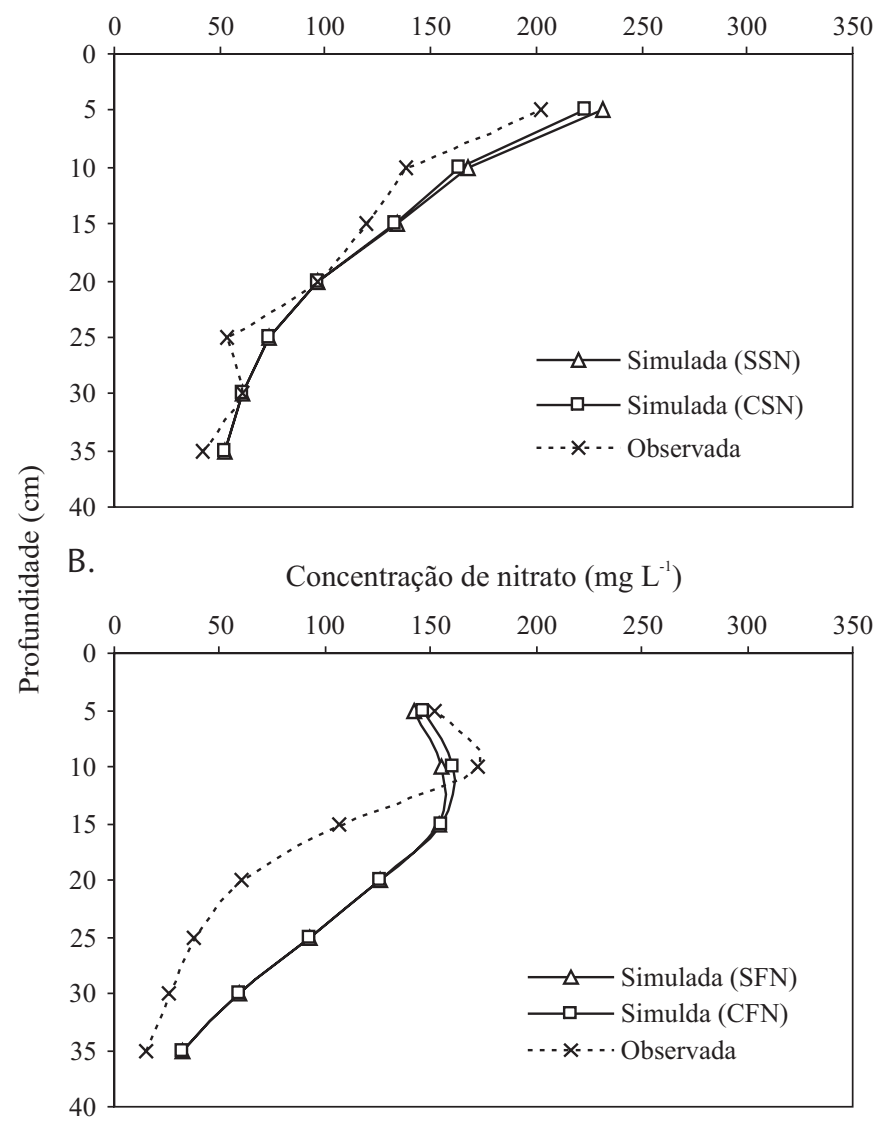

Figura 3. Perfis de concentração de $\mathrm{NH}_{4}+\left(\right.$ A) e $\mathrm{NO}_{3}-$ (B) em solo muito argiloso, observados e simulados pelo modelo SIMASS-C, sem fonte de $\mathrm{N}$ (SFN) e com fonte de $\mathrm{N}$ (CFN), para o $\mathrm{NO}_{3}{ }^{-}$, e sem sumidouro $\mathrm{N}$ (SSN) e com sumidouro de $\mathrm{N}(\mathrm{CSN})$, para o $\mathrm{NH}_{4}^{+}, 10$ dias após aplicação da primeira lâmina de irrigação 
Entre os perfis mostrados nas Figuras 3A e 4A, notou-se grande redução na concentração de amônio entre a primeira e segunda irrigações, semelhante ao solo franco-argilo-arenoso, não havendo aumento proporcional de nitrato para o mesmo período (Figuras 3B e 4B), confirmando a hipótese de desnitrificação, exceto nos primeiros $20 \mathrm{~cm}$ de profundidade (Figura 4A). Diferente do ocorrido com o solo francoargilo-arenoso, o amônio não desapareceu totalmente abaixo de $30 \mathrm{~cm}$ de profundidade no solo muito argiloso.

$$
\text { A. }
$$

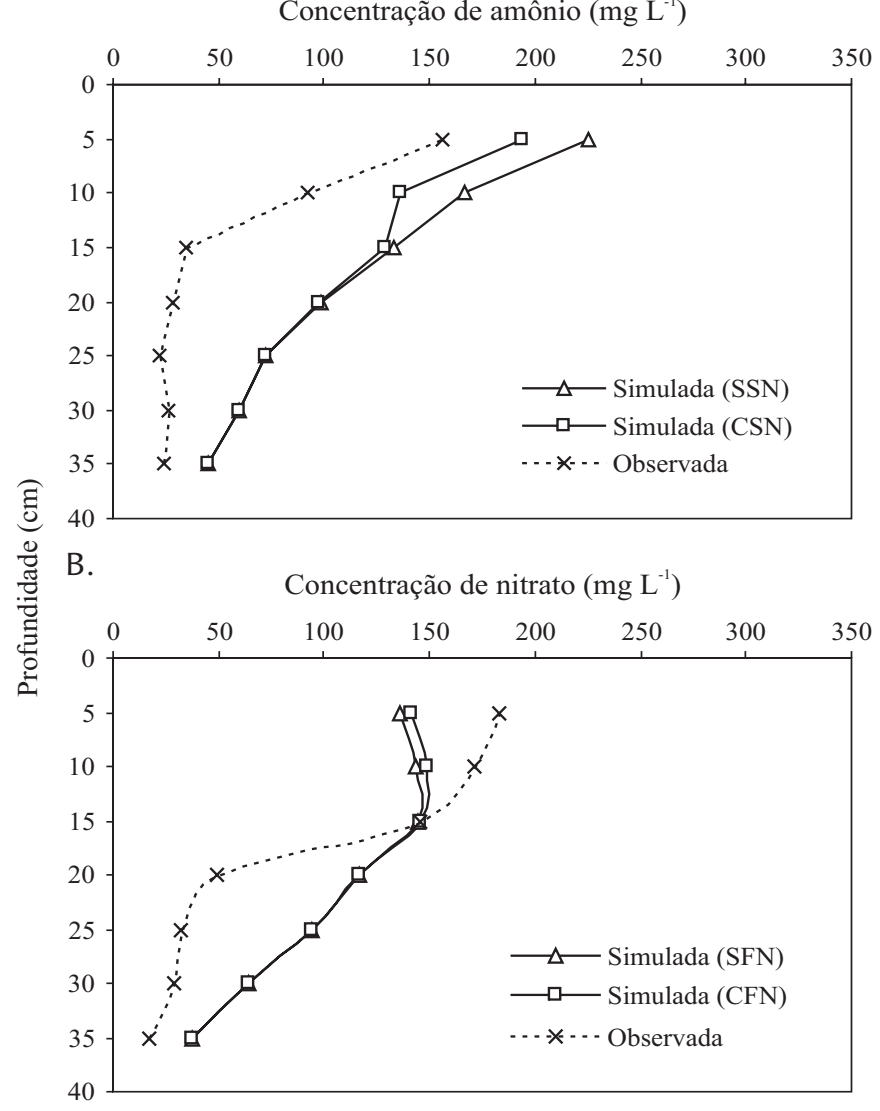

Figura 4. Perfis de concentração de $\mathrm{NH}_{4}{ }^{+}$(A) e $\mathrm{NO}_{3}{ }_{3}^{-}$(B) em solo muito argiloso, observados e simulados pelo modelo SIMASS-C, sem fonte de $\mathrm{N}$ (SFN) e com fonte de $\mathrm{N}$ (CFN), para o $\mathrm{NO}_{3}^{-}$, e sem sumidouro $\mathrm{N}$ (SSN) e com sumidouro de $\mathrm{N}(\mathrm{CSN})$, para o $\mathrm{NH}_{4}^{+}, 10$ dias após aplicação da segunda irrigação

\section{CONCLUSÕES}

1. A temperatura e a umidade afetaram as transformações de nitrogênio, cujos efeitos foram mais pronunciados a partir de 15 dias de incubação, principalmente nas temperaturas acima de $25^{\circ} \mathrm{C}$ e umidades iguais ou superiores à capacidade de campo.

2. Ao se estimular as reações biológicas sofridas pelo $\mathrm{N}$, a altos teores de água no solo, causaram maiores erros entre as concentrações de nitrato e amônio simuladas e observadas.

3. Na movimentação do N no solo, além das características físico-hídricas do solo, as reações biológicas devem ser consideradas, principalmente quando a temperatura e umidade são elevadas.

\section{LITERATURA CITADA}

Bernardo, S. Impacto ambiental da irrigação no Brasil. In: Conferência sobre Agricultura e Meio Ambiente, 1992, Viçosa. Anais... Viçosa: Núcleo de Estudos e Pesquisas em Meio Ambiente, 1994. p.93-100.

Black, A. S.; Waring, S. A. Nitrate leaching and adsorption in a krasnozem from redland bay. II - Soil factors influencing adsorption. Australian Journal Soil Research, v.14, n.2, p.181188, 1976a.

Black, A. S.; Waring, S. A. Nitrate leaching and adsorption in a krasnozem from redland bay. III - Effect of nitrate concentration on adsorption and movement in soil columns. Australian Journal Soil Research, v.14, n.2, p.189-195, 1976 b.

Campbell, C. A.; Biederbeck, V. O. Changes in mineral N and numbers of bacteria and actinomycetes during two years under wheat-fallow in Southwestern Saskatchewan. Canadian Journal of Soil Science, v.62, p.125-137, 1982.

Corrêa, M. M. Desenvolvimento e teste de modelo de transporte unidimensional de solutos no solo. Viçosa: UFV, 2001.104p. Tese Doutorado

EMBRAPA - Empresa Brasileira de Pesquisa Agropecuária. Manual de métodos de analise de solo. 2.ed., Rio de Janeiro: Embrapa CNPS, 1997. 212p.

Ferreira, P. A.; Ribeiro, A. C.; Santos, C. R.; Henriques, H. P.; Caixeta, T. J. Movimento vertical de nitrato, amônio, cloreto e potássio em colunas de solo irrigado. Revista Ceres, Viçosa, v.210, v.37, p.152-166, 1990.

Gomes, T. M.; Saad, J. C. C.; Cruz, R. L.; Dias, C. T. S. Avaliação da concentração e distribuição de nitrito, amônio e nitrato provenientes da uréia aplicada via sistema de irrigação por gotejamento. Scientia Agrícola, Piracicaba, v.9, p.73-79, 1998.

Gonçalves, J. L. M.; Carlyle, J. C. Modelling the influence of moisture and temperature on net nitrogen mineralization in a forested sandy soil. Soil Biology and Biochemistry, v.26, n.11, p.1557-1564, 1994.

Kempers, A. J.; Zweers, A. Ammonium determination in soil extracts by the salicylate method. Community in Soil Science Plant Analysis, New York, v.17, n.7, p.715-723, 1986.

Muchovej, R. M. C.; Rechcigl, J. E. Impact of nitrogen fertilization of pastures and turfgrasses on water quality.In: Lal, R.; Stewart, B.A. (ed.). Soil Processes and water quality, Boca Raton: Lewis Publishers. 1994. p.91-135.

Owens, L. B. Impacts of soil $\mathrm{N}$ management on the quality of surface and subsurface water In: Lal, R.; Stewart, B. A. (ed.). Soil Processes and water quality, Boca Raton: Lewis Publishers. 1994. p.137-162.

Reis, T. C.; Rondella, A. A. Cinética de degradação da matéria orgânica e variação do $\mathrm{pH}$ do solo sob diferentes temperaturas. Revista Brasileira de Ciência do Solo, Viçosa, v.26, p.619-626. 2002.

Serrano, M. I. P. Mineralização, absorção e lixiviação de nitrogênio em povoamentos de Eucalyptus grands sob cultivo mínimo e intensivo do solo. Piracicaba: ESALQ, 1997. 86p. Dissertação Mestrado

Sierra, J. Temperature and soil moisture dependence of n mineralization in intact soil cores. Soil Biology and Biochemistry, v.29, p.1557-1563, 1997. 
Stanford, G.; Epstein, L. Nitrogen mineralization - Water relations in soils. Soil Science Society of America Proceedings, v.38, p.103-106, 1974.

Stark J. M.; Firestone, M. K. Mechanisms for soil moisture effects on activity of nitrifying bacteria. Applied and Environmental Microbiology, v.61, p.218-221, 1995.
Strong, D. T.; Fillery, I. R. P. Denitrification response to nitrate concentrations in sandy soils. Soil Biology and Biochemistry, v.24, p.945-954, 2002.

Yang, J. E.; Skogley, E. O.; Schaff, B. E.; Kim, J. J. A simple Spectrophotometric determination of nitrate in water, resin and soil extracts. Soil Science Society American Journal, v.62, p.1108-1115, 1998. 